\title{
Determination of Residual Solvents in Bulk Pharmaceuticals by Thermal Desorption/Gas Chromatography/Mass Spectrometry
}

\author{
Koji Urakami, ${ }^{* a}$ Yuka Saito, ${ }^{b}$ Yasuhiro Fujiwara, ${ }^{b}$ Chuichi Watanabe, ${ }^{c}$ Kazuichi Umemoto, ${ }^{a}$ \\ Masayuki Godo, ${ }^{a}$ and Keiji Hashimoto ${ }^{b}$ \\ Analysis \& Quality Control Department, Takeda Chemical Industries, Ltd., ${ }^{a}$ 2-17-85 Jusohonmachi Yodogawa-ku, Osaka \\ 532-8686, Japan, Kyoto Pharmaceutical University, ${ }^{b} 5$ Nakauchicho Misasagi Yamashina-ku, Kyoto 607-8414, Japan, and \\ Frontier LAB, Co., Ltd., "61-2 Otsubo Otsukicho, Koriyama, Fukushima 963-0201, Japan. \\ Received June 2, 2000; accepted August 3, 2000
}

Thermal desorption (TD) techniques followed by capillary GC/MS were applied for the analysis of residual solvents in bulk pharmaceuticals. Solvents desorbed from samples by heating were cryofocused at the head of a capillary column prior to GC/MS analysis. This method requires a very small amount of sample and no sample pretreatment. Desorption temperature was set at the point about $20^{\circ} \mathrm{C}$ higher than the melting point of each sample individually. The relative standard deviations of this method tested by performing six consecutive analyses of 8 different samples were 1.1 to $3.1 \%$, and analytical results of residual solvents were in agreement with those obtained by direct injection of $\mathrm{N}, \mathrm{N}$-dimethylformamide solution of the samples into the GC. This novel TD/GC/MS method was demonstrated to be very useful for the identification and quantification of residual solvents in bulk pharmaceuticals.

Key words thermal desorption; GC/MS; residual solvent; bulk pharmaceutical

The analysis of residual solvents in pharmaceuticals is very important because of the potential risk to human health from the toxicity of many of these solvents ${ }^{1)}$; the amounts of such solvents are therefore restricted by International Conference on Harmonization (ICH) guidelines. ${ }^{2)}$ Gas chromatography $(\mathrm{GC})$ is generally used to determine residual solvents because of its excellent separation ability and low detection limit. Samples are dissolved in a suitable solvent followed by direct injection (DI) ${ }^{3,4)}$ or headspace sampling, ${ }^{5,6)}$ or are extracted with a suitable solvent. ${ }^{7,8}$ Although the DI method is both rapid and convenient, less volatile sample components or dissolving solvents could interfere with the subsequent analysis, and interactions between dissolving solvents and other sample components in the injection port can cause various problems. ${ }^{9)}$ Headspace sampling has the advantage of introducing only a limited number of solvents onto the GC column, however, it requires specialized apparatus and is an imprecise analysis. Solvent extraction may introduce experimental problems such as selectivity of extraction, inconvenient sample treatment, and variable recoveries.

Thermal desorption (TD) followed by GC/MS has been successfully employed in the analysis of volatile compounds in many samples ${ }^{10-14)}$; several kinds of pyrolyzers have been used in these studies. However, few studies applying this technique to the determination of residual solvents in pharmaceuticals have been performed ${ }^{14)}$; moreover, they are not based on quantitative determination.

The aim of the work described here was to develop and evaluate a new method for the identification and quantification of residual solvents in bulk pharmaceuticals on capillary GC/MS without sample pretreatment, such as dissolution in a solvent or solvent extraction. This method was based on TD of residual solvents from samples using a double shot pyrolyzer. Desorbed solvents are cryofocused at the head of a separation column prior to capillary GC/MS analysis. To investigate the optimum conditions for the determination method, 8 different bulk pharmaceuticals containing various residual solvents were used.

\section{Experimental}

Materials and Reagents Ethyl aminobenzoate and phenacetin were commercial products of JP XIII grade and obtained from Maruishi Pharmaceutical Co., Ltd. (Osaka, Japan). Isoniazid was a commercial product of JP XIII grade from Daiichi Pharmaceutical Co., Ltd. (Tokyo, Japan). Other samples were of biochemical grade and obtained from Wako Pure Chemical Industries, Ltd. (Osaka). Solvents were of reagent grade and also obtained from Wako Pure Chemical Industries, Ltd.

TD of Residual Solvents in Pharmaceutical Samples A vertical furnace-type double shot pyrolyzer (Frontier Lab Co., Ltd., Koriyama, Japan) mounted on top of a Shimadzu Model QP5050A GC/MS with an electron impact ion source was used. Figure 1 shows the schematic diagram of this pyrolyzer.

About $1 \mathrm{mg}$ of a sample accurately weighed was placed inside the sample cup $(5.0 \mathrm{~mm} \times 3.8 \mathrm{~mm}$ i.d. $)$ and TD was performed. TD was achieved at 100 ${ }^{\circ} \mathrm{C}$, or by raising the temperature of the furnace from $100^{\circ} \mathrm{C}$ to the desired temperature $\left(120\right.$ to $220^{\circ} \mathrm{C}$ range $)$ at a rate of $50^{\circ} \mathrm{C} / \mathrm{min}$. The TD period was set for $3 \mathrm{~min}$. The volatile substances were desorbed from the sample in a stream of carrier gas and collected at the head of a capillary column, where

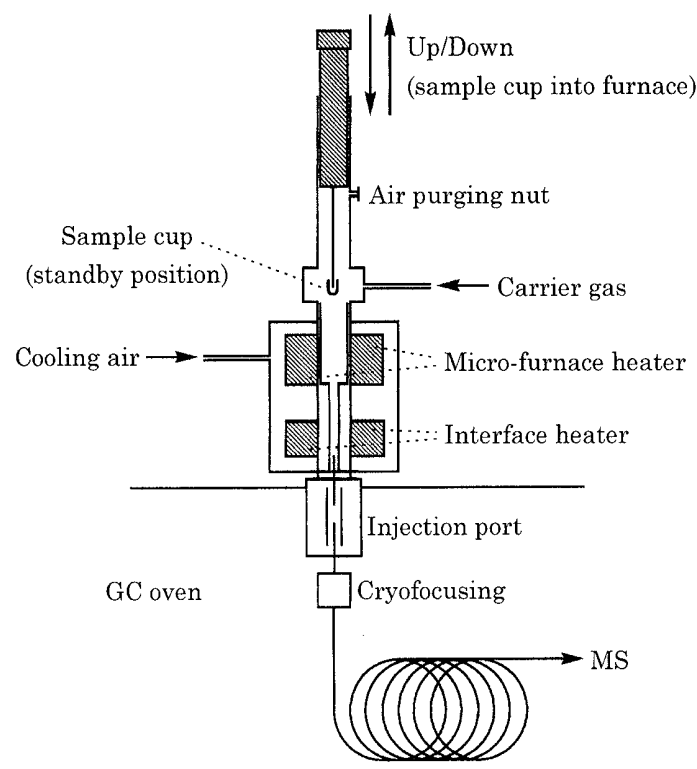

Fig. 1. Schematic Diagram of Vertical Furnace-type Double Shot Pyrolyzer 
cryogenic cooling was done with liquid nitrogen during the period of TD. By discontinuing cryofocusing, the temperature of the column head was raised to $40^{\circ} \mathrm{C}$ (initial column oven temperature), and the trapped compounds were transferred to an analytical column.

Standard Preparation for TD Based Analysis Stock standard solvents were prepared by weighing approximately $1.0 \mathrm{~g}$ of methanol, ethanol, acetone, toluene, and heptane into a $20-\mathrm{ml}$ volumetric flask, diluting to volume with $N, N$-dimethyformamide (DMF), and mixing. Further, standard solvents for calibration were prepared by suitably diluting the stock standard solvents with DMF to give solutions over the concentration range of 25 to 1000 $\mu \mathrm{g} / \mathrm{ml}$, which corresponds to a solvent level of 25 to $1000 \mathrm{ppm}$ by weight in the sample. One microliter of these standard solvents was transferred into a sample cup for calibration, and heated up to $160^{\circ} \mathrm{C}$ with cryofocusing in the above manner

GC and MS Conditions for TD Based Analysis The column used was a $30 \mathrm{~m} \times 0.25 \mathrm{~mm}$ i.d. fused silica column coated with a $0.5 \mu \mathrm{m}$ film of polyethyleneglycol (DB-Wax, J\& W Scientific Co., Ltd., Folsom, CA, U.S.A.). The split injection mode was used with an approximate splitting ratio of $1: 50$. The carrier gas was helium, the average column linear velocity was about $35 \mathrm{~cm} / \mathrm{s}$, and injector temperature was $270^{\circ} \mathrm{C}$. The column temperature was programmed at $40^{\circ} \mathrm{C}$ for $5 \mathrm{~min}$, increased to $175^{\circ} \mathrm{C}$ at $8{ }^{\circ} \mathrm{C} / \mathrm{min}$, then to $250^{\circ} \mathrm{C}$ at $35^{\circ} \mathrm{C} / \mathrm{min}$, and finally maintained at $250^{\circ} \mathrm{C}$ for at least 16 min. Mass spectra were recorded under electron-impact ionization at $70 \mathrm{eV}$ from $\mathrm{m} / z 35$ to 300 and the ion source was maintained at $280^{\circ} \mathrm{C}$.

Sample and Standard Preparation for DI Based Analysis Approximately $0.1 \mathrm{~g}$ of a sample was weighed, put into a 5 -ml volumetric flask, dissolved and diluted to the volume with DMF, and mixed. Standard solvents were prepared by diluting with the stock standard solvents, described in the previous section, 10000 times with DMF, which corresponds to a solvent level of $250 \mathrm{ppm}$ by weight in the sample. Equal volumes (about $1 \mu \mathrm{l}$ ) of the sample and standard were separately injected into the GC

GC Conditions for DI Based Analysis Quantitative analyses were performed on a Shimadzu Model GC-15A gas chromatograph equipped with a flame ionization detector and a Shimadzu Model AOC-17 auto injector. Sample and standard solutions were injected in the direct mode. The analytical column used was a $30 \mathrm{~m} \times 0.53 \mathrm{~mm}$ i.d. fused silica column coated with a $5.0 \mu \mathrm{m}$ film of $5 \%$ diphenyl, 95\% dimethylsiloxane (SPB-5, Supelco Co., Ltd., Bellefonte, PA, U.S.A.). A $5 \mathrm{~m} \times 0.53 \mathrm{~mm}$ i.d. fused silica column coated with $0.5 \mu \mathrm{m}$ film of SPB-5 was used as a guard column to retain the injected compounds and prevent contamination of the analytical column.

Table 1. List of Sample Names and Residual Solvents Contained

\begin{tabular}{lllr}
\hline \hline No. & \multicolumn{1}{c}{ Sample } & Residual solvent & Class \\
\hline 1 & Lidocaine & Heptane & 3 \\
2 & Ethyl aminobenzoate & Toluene & 2 \\
3 & Antipyrine & Methanol & 2 \\
4 & Phenacetin & Methanol, toluene & 2,2 \\
5 & Cimetidine & Ethanol & 3 \\
6 & Famotidine & Methanol & 2 \\
7 & Isoniazid & Methanol & 2 \\
8 & Carbamazepine & Acetone & 3 \\
\hline
\end{tabular}

The carrier gas was helium, and the average column linear velocity determined by injections of methane was about $35 \mathrm{~cm} / \mathrm{s}$. Nitrogen was used as the make-up gas at a flow rate of $50 \mathrm{ml} / \mathrm{min}$. The injector and detector temperatures were 140 and $260^{\circ} \mathrm{C}$, respectively. The column temperature was programmed at $35^{\circ} \mathrm{C}$ for $10 \mathrm{~min}$, raised to $175^{\circ} \mathrm{C}$ at $8{ }^{\circ} \mathrm{C} / \mathrm{min}$, then to $260^{\circ} \mathrm{C}$ at $35^{\circ} \mathrm{C} / \mathrm{min}$, and finally maintained at $260^{\circ} \mathrm{C}$ for at least $16 \mathrm{~min}$. The injection volume was $1.0 \mu \mathrm{l}$.

\section{Results and Discussion}

Effect of Desorption Temperature The effect of temperature on the TD was examined using 8 different samples in a 100 to $220^{\circ} \mathrm{C}$ range. Table 1 lists the sample names together with the residual solvents contained. These solvents are classified as Class 2 (solvents to be limited) or Class 3 (solvents with low toxic potential) based on the ICH guidelines. ${ }^{2)}$

Desorption at high temperature may be accompanied by the pyrolysis of samples, while low temperature may result in the incomplete desorption of solvents. Therefore, TD was performed at a temperature range set for each individual sample. A desorption period of $3 \mathrm{~min}$ seemed advisable, since a longer period increased overall analysis time and consumed a large quantity of the liquid nitrogen for the cryofocusing. Quantitative data were calculated from total ion current (TIC) peak areas. The results are summarized in Table 2 and are expressed as the relative value (\%) to the maximum amount of the solvent found in the sample.

When desorption temperature was at least $20^{\circ} \mathrm{C}$ higher than the melting point of each sample, desorption of solvents reached a plateau. This desorption characteristic was observed regardless of the kinds of sample and residual solvent. Although famotidine started to pyrolyze above its melting (decomposition) point, it did not interfere with the analysis. Taking into account the damage of the analytical column caused by pyrolytic compounds, TD temperature was set at a point about $20^{\circ} \mathrm{C}$ higher than the melting point of each sample.

Standard Linearity The linearity of the relationship between peak area and concentration (ppm) for the 5 solvents contained in the samples (Table 1) used in the present study was investigated by linear regression analysis by the method of least squares. The linear range investigated for each solvent was from 25 to $1000 \mathrm{ng}$, which corresponds to a solvent level of 25 to $1000 \mathrm{ppm}$ based on a sample amount of $1 \mathrm{mg}$. The equation of the best-fit line was found for each solvent. The detection limits of these solvents were defined as the

Table 2. Effect of Temperatures on the Desorption of Residual Solvents for Different Samples

\begin{tabular}{|c|c|c|c|c|c|c|c|c|c|}
\hline \multirow{2}{*}{ Sample ${ }^{a)}$} & \multirow{2}{*}{$\begin{array}{c}\text { Melting } \\
\text { point }\left({ }^{\circ} \mathrm{C}\right)\end{array}$} & \multirow{2}{*}{$\begin{array}{c}\text { Residual } \\
\text { solvent }\end{array}$} & \multicolumn{7}{|c|}{ Relative concentration (\%) } \\
\hline & & & $100^{\circ} \mathrm{C}$ & $120^{\circ} \mathrm{C}$ & $140^{\circ} \mathrm{C}$ & $160^{\circ} \mathrm{C}$ & $180^{\circ} \mathrm{C}$ & $200^{\circ} \mathrm{C}$ & $220^{\circ} \mathrm{C}$ \\
\hline 1 & 68 & Heptane & 99.3 & 99.6 & 99.6 & 100.0 & - & - & - \\
\hline 2 & 89 & Toluene & 99.7 & 100.0 & 99.9 & 99.4 & - & - & - \\
\hline 3 & 112 & Methanol & 83.4 & 99.5 & 100.0 & 98.7 & - & - & - \\
\hline 4 & 134 & Methanol & - & 84.1 & 99.2 & 100.0 & 99.6 & - & - \\
\hline 5 & 142 & Ethanol & - & 0 & 84.2 & 98.3 & 99.6 & 100.0 & 99.9 \\
\hline 6 & 163 & Methanol & - & 2.5 & 4.8 & 96.9 & 100.0 & 98.9 & 99.4 \\
\hline 7 & 171 & Methanol & - & 0 & 93.1 & 99.8 & 100.0 & 98.8 & 99.8 \\
\hline 8 & 191 & Acetone & - & 7.4 & 24.8 & 87.9 & 100.0 & 98.9 & 99.6 \\
\hline
\end{tabular}

a) Numbers refer to sample listed in Table 1. Data are expressed as the relative value (\%) to the maximum amount of solvent found in the sample.

Data in bold are within the plateau range. Data indicated by - are not determined. 
concentration which would give a peak height equal to three times the baseline noise. The slopes and intercepts of the best-fit lines, the correlation coefficients and detection limits for each solvent are presented in Table 3. Figure 2B shows a typical chromatogram of standard containing 5 solvents at concentrations of $500 \mathrm{ppm}$ by weight in the sample. No appreciable difference was observed in the retention time between sample and standard analysis.

Method Precision and Accuracy (Recovery) The precision of the proposed method was tested by performing six consecutive TD/GC/MS analyses using all samples. Temperature of TD was set at a point about $20^{\circ} \mathrm{C}$ higher than the melting point of each sample, as described above. The mean contents of residual solvents and relative standard deviations (RSDs) were calculated and compared with those obtained by conventional DI/GC method; the results are given in Table 4.

In spite of the very small sample amount used ( $1 \mathrm{mg})$, each sample has an RSD of less than $3.5 \%$, indicating almost the same precision as the DI/GC method. To evaluate the accuracy, the percentage recoveries were calculated as the relative value of the amount obtained by the proposed method to those obtained by the DI/GC method (Table 4). The results show virtually complete accuracy $(95.7-102.1 \%)$ of the solvents in every sample, and solvents detected by DI/GC method could also be detected by TD/GC/MS method. These satisfactory data of method precision and accuracy at the concentration level from 50 to $800 \mathrm{ppm}$ suggest that Class 1 solvents (the lowest concentration limit is $2 \mathrm{ppm}$ ) in the $\mathrm{ICH}$ guidelines could not be determined, however, Class 2 solvents (the lowest concentration limit is $50 \mathrm{ppm}$ ) could be by the proposed method. Figures $2 \mathrm{C}-\mathrm{J}$ shows typical chromatograms from analyses of the samples.

Table 3. Linearity Data for the Solvents Analyzed by the Proposed TD/GC/MS Method

\begin{tabular}{lcccc}
\hline \hline Solvent & Slope & Intercept & $\begin{array}{c}\text { Correlation } \\
\text { coefficient }(r)\end{array}$ & $\begin{array}{c}\text { Detection } \\
\text { limit }(\mathrm{ppm})\end{array}$ \\
\hline Heptane & $2.432 \times 10^{4}$ & $6.309 \times 10^{3}$ & 1.0000 & 2 \\
Acetone & $1.310 \times 10^{4}$ & $2.317 \times 10^{2}$ & 0.9995 & 5 \\
Methanol & $1.305 \times 10^{4}$ & $1.210 \times 10^{3}$ & 0.9996 & 25 \\
Ethanol & $1.612 \times 10^{4}$ & $7.686 \times 10^{3}$ & 1.0000 & 25 \\
Toluene & $2.697 \times 10^{4}$ & $7.447 \times 10^{3}$ & 1.0000 & 10 \\
\hline
\end{tabular}

\section{Conclusion}

We have demonstrated that the proposed novel TD/GC/MS method is very useful for the identification and quantification of residual solvents in bulk pharmaceuticals. The conventional method of GC analysis of residual solvents in these pharmaceuticals requires sample pretreatment such as disso-
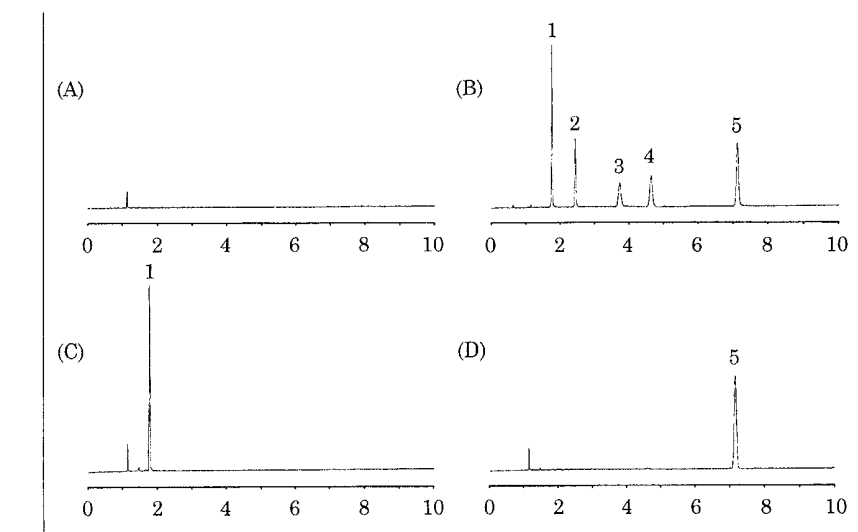

(E)

(F)
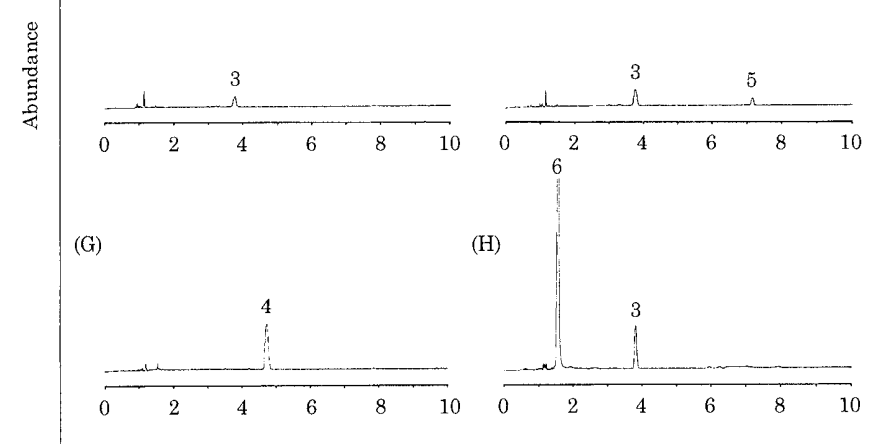

(I)

(J)
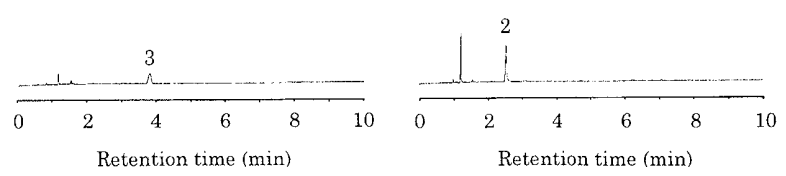

Fig. 2. TD/GC/MS Chromatograms Obtained from Blank, Standard and Samples

(A) Blank, (B) standard (500 ppm of each solvent), (C) lidocaine, (D) ethyl aminobenzoate, (E) antipyrine, (F) phenacetin, $(\mathrm{G})$ cimetidine, $(\mathrm{H})$ famotidine, (I) isoniazid, $(\mathrm{J})$ carbamazepine. Peaks: $1=$ heptane, $2=$ acetone, $3=$ methanol, $4=$ ethanol, $5=$ toluene, $6=$ thermal degradation compound.

Table 4. Analytical Results of 8 Different Samples by TD/GC/MS Method

\begin{tabular}{|c|c|c|c|c|c|c|c|}
\hline \multirow{2}{*}{ Sample } & \multirow{2}{*}{$\begin{array}{c}\text { Residual } \\
\text { solvent }\end{array}$} & \multirow{2}{*}{$\begin{array}{c}\text { Desorption } \\
\text { temperature } \\
\left({ }^{\circ} \mathrm{C}\right)\end{array}$} & \multicolumn{2}{|c|}{$\mathrm{TD} / \mathrm{GC} \mathrm{MS}^{a)}$} & \multicolumn{2}{|c|}{$\mathrm{DI} / \mathrm{GC}^{a}$} & \multirow{2}{*}{$\begin{array}{c}\text { Accuracy }{ }^{h)} \\
(\%)\end{array}$} \\
\hline & & & $\begin{array}{l}\text { Mean value } \\
\text { (ppm) }\end{array}$ & $\begin{array}{c}\mathrm{RSD} \\
(\%)\end{array}$ & $\begin{array}{l}\text { Mean value } \\
\quad(\mathrm{ppm})\end{array}$ & $\begin{array}{l}\text { RSD } \\
(\%)\end{array}$ & \\
\hline Lidocaine & Heptane & 100 & 565 & 2.7 & 590 & 2.5 & 95.8 \\
\hline Ethyl aminobenzoate & Toluene & 110 & 736 & 2.5 & 756 & 3.1 & 97.4 \\
\hline Antipyrine & Methanol & 130 & 232 & 2.2 & 239 & 4.7 & 97.1 \\
\hline \multirow[t]{2}{*}{ Phenacetin } & Methanol & 155 & 340 & 2.8 & 345 & 5.2 & 98.6 \\
\hline & Toluene & & 56 & 2.9 & 56 & 3.6 & 100.0 \\
\hline Cimetidine & Ethanol & 160 & 877 & 2.4 & 888 & 2.9 & 98.8 \\
\hline Famotidine & Methanol & 185 & 697 & 3.1 & 715 & 1.4 & 97.5 \\
\hline Isoniazid & Methanol & 190 & 230 & 2.4 & 225 & 4.2 & 102.2 \\
\hline Carbamazepine & Acetone & 210 & 289 & 1.1 & 290 & 1.6 & 99.7 \\
\hline
\end{tabular}

a) Results of 6 analyses. b) Determined as the percent recovery by [(concentration obtained from TD/GC/MS)/(concentration from $\mathrm{DI} / \mathrm{GC}) \times 100]$. 
lution of the sample in a solvent or solvent extraction using more than $100 \mathrm{mg}$ of sample. The proposed method, based on direct TD followed by GC/MS analysis, eliminates the need for such pretreatment as well as the possibility of interaction between dissolving solvent and other sample components in the injection port; moreover, it reduces the sample amount required to $1 \mathrm{mg}$. To achieve sufficient precision and accuracy, this technique requires strict control of desorption temperatures set for individual samples.

Acknowledgments The authors thank Mr. Shunji Terada for constructive advice and suggestions.

\section{References}

1) Witschi C., Doelker E., Eur. J. Pharm. Biopharm., 43, 215-242 (1997).

2) ICH guidelines for residual solvents Q3C Step 4, 17 July 1997.

3) Haky J. E., Stickney T. M., J. Chromatogr., 321, 137-144 (1985).
4) Smith I. D., Waters D. G., Analyst, 116, 1327-1331 (1991).

5) Markovich R. J., Ong S., Rosen J., J. Chromatogr. Sci., 35, 584-592 (1997).

6) Ruchatz F., Kleinebudde P., Müller B. W., Int. J. Pharm., 142, 67-73 (1996).

7) Matsui F., Lovering E. G., Watson J. R., Black D. B., Sears R. W., J. Pharm. Sci., 73, 1664-1666 (1984).

8) Noda H., Minemoto M., Tamari K., Yakuzaigaku, 44, 128-133 (1984).

9) Kersten B. S., J. Pharm. Sci., 30, 115-119 (1992).

10) Esteban J. L., Martínez-Castro I., Sanz J., J. Chromatogr. A, 657, $155-164$ (1993)

11) Wahl H. G., Hoffmann A., Häring H. U., Liebich H. M., J. Chromatogr. A, 847, 1-7 (1999).

12) Hung I. F., Lee S. A., Chen R. K., J. Chromatogr. B, 706, 352--357 (1998).

13) García-Romero E., Pérez-Caello M. S., Sanz J., Cabezudo M. D., Analusis, 26, $33-35$ (1998).

14) Fabbri A., Crescentini G., Mangani F., Mastrogiacomo A. R., Bruner F., Chromatographia, 23, 856-860 (1987). 